\title{
Green mitigation strategy for cultural heritage: bacterial potential for biocide production
}

\author{
Mara Silva $^{1,2}$ - Tânia Rosado ${ }^{2}$ - Dora Teixeira ${ }^{1,2}$ • António Candeias ${ }^{1,2}$. \\ Ana Teresa Caldeira ${ }^{1,2}$
}

Received: 15 August 2016/Accepted: 28 November 2016

(C) Springer-Verlag Berlin Heidelberg 2016

\begin{abstract}
Several biosurfactants with antagonistic activity are produced by a variety of microorganisms. Lipopeptides (LPPs) produced by some Bacillus strains, including surfactin, fengycin and iturin are synthesized nonribosomally by mega-peptide synthetase (NRPS) units and they are particularly relevant as antifungal agents. Characterisation, identification and evaluation of the potentials of several bacterial isolates were undertaken in order to establish the production of active lipopeptides against biodeteriogenic fungi from heritage assets. Analysis of the iturin operon revealed four open reading frames (ORFs) with the structural organisation of the peptide synthetases. Therefore, this work adopted a molecular procedure to access antifungal potential of LPP production by Bacillus strains in order to exploit the bioactive compounds synthesis as a green natural approach to be applied in biodegraded cultural heritage context. The results reveal that the bacterial strains with higher antifungal potential exhibit the same morphological and biochemical characteristics, belonging to the genera Bacillus. On the other hand, the higher iturinic genetic expression, for Bacillus sp. 3 and Bacillus sp. 4 , is in accordance with the culture antifungal spectra. Accordingly, the adopted methodology combining antifungal screening and molecular data is represent a valuable tool for quick identification of iturin-producing strains, constituting an
\end{abstract}

Responsible editor: Philippe Garrigues

Ana Teresa Caldeira

atc@uevora.pt

1 Chemistry Department, School of Sciences and Technology, Évora University, Rua Romão Ramalho 59, 7000-671 Évora, Portugal

2 HERCULES Laboratory, Évora University, Largo Marquês de Marialva 8, 7000-809 Évora, Portugal effective approach for confirming the selection of lipopeptides producer strains.

Keyword Green biocides - Cultural heritage - Bacillus sp. · Biosurfactants $\cdot$ Lipopeptides $\cdot$ Antifungal activity $\cdot$ Peptide synthetase

\section{Introduction}

Biosurfactants are biological surface-active compounds largely produced by a wide variety of microorganisms (DehghanNoude et al. 2005; Das et al. 2008; Cao et al. 2009). An extensive range of structurally different biosurfactants have been identified, including glycolipids, lipoproteins, polysaccharides, proteins and lipopeptides (Souto et al. 2004; Roongsawang et al. 2010). Lipopeptides molecules are commonly made up of a hydrophobic portion composed by fatty acids (saturated, unsaturated or hydroxylated), which are linked to a short linear or cyclic oligopeptide, that mark the hydrophilic portion of the molecule (Raaijmakers et al. 2010). On the basis of the structural relationships, the lipopeptides that have been identified in some Bacillus strains are generally classified into three groups: the surfactin group (Yao et al. 2003; Mikkola et al. 2004), the fengycin group ( $\mathrm{Hu}$ et al. 2007; Arrebola et al. 2010) and the iturin group (Moyne et al. 2001; Kim et al. 2010; Mandal et al. 2013).

The members of the surfactin and fengycin groups are composed of one $\beta$-hydroxy fatty acid and 7 or $10 \alpha$-amino acids, respectively, while the members of the iturin group consist of one $\beta$-amino fatty acid and $7 \alpha$-amino acids. The presence of the $\beta$-amino fatty acid is the most striking characteristic of the iturin A family and distinguishes this from the other two families (Tsuge et al. 2001). 